\title{
Right Hepatic Artery Pseudoaneurysm Complicating Acute Pancreatitis: A Case Report
}

\author{
Kazue Shiozawa Manabu Watanabe Takashi lkehara Takanori Mukozu \\ Itaru Kamata Yui Kishimoto Takahiko Mimura Ken Ito Naoki Okano \\ Yoshinori Igarashi Yasukiyo Sumino
}

Division of Gastroenterology and Hepatology, Department of Internal Medicine, Toho University Medical Center, Omori Hospital, Tokyo, Japan

\section{Key Words}

Pseudoaneurysm • Right hepatic artery • Acute pancreatitis • Angiography

\begin{abstract}
Objective: To report a rare case of right hepatic artery pseudoaneurysm complicating acute pancreatitis based upon imaging findings obtained before and after the development of pseudoaneurysm. Clinical Presentation and Intervention: A 32-year-old male with a history of acute pancreatitis 1 year prior was readmitted for acute pancreatitis. Computed tomography (CT) and angiography after admission revealed pseudoaneurysm of the right hepatic artery. Transcatheter arterial embolization with coils was used to successfully treat the pseudoaneurysm. A CT and angiography 1 year earlier did not reveal any pseudoaneurysm. Conclusion: This patient with a rare right hepatic artery pseudoaneurysm complicating acute pancreatitis was successfully treated with coil embolization.
\end{abstract}

\section{Introduction}

Acute pancreatitis can exhibit a severe disease course in $20-30 \%$ of the cases, and may be complicated by lifethreatening conditions, including multi-organ failure and hemorrhage resulting from pseudoaneurysm or pseudocyst [1]. Pseudoaneurysms account for $4-10 \%$ of these complications [2]. Once a rupture of a pseudoaneurysm occurs, the mortality has been reported to be high if left untreated (90\%) and when treated it was $15-50 \%$ [2]; thus, early diagnosis and treatment are considered to be essential. Transcatheter arterial embolization had been considered safe and effective for pseudoaneurysm of this kind [3].

In this study, we encountered a rare case of right hepatic artery pseudoaneurysm complicating acute pancreatitis. Moreover, in this patient, image findings were obtained before and after development of the pseudoaneurysm to confirm that the acute pancreatitis caused the pseudoaneurysm and to demonstrate that the disease could be diagnosed and treated promptly without allowing it to rupture.

\begin{tabular}{ll}
\hline KARGER & $\begin{array}{l}\text { ○ 2012 S. Karger AG, Basel } \\
1011-7571 / 13 / 0224-0402 \$ 38.00 / 0 \quad \text { Karger }\end{array}$ \\
$\begin{array}{l}\text { E-Mail karger@karger.com } \\
\text { www.karger.com/mpp }\end{array}$ & $\begin{array}{l}\text { This is an Open Access article licensed under the terms of the } \\
\text { Creative Commons Attribution-NonCommercial 3.0 Un- } \\
\text { ported license (CC BY-NC) (www.karger.com/OA-license), } \\
\text { applicable to the online version of the article only. Distribu- } \\
\text { tion permitted for non-commercial purposes only. }\end{array}$
\end{tabular}

Manabu Watanabe

Division of Gastroenterology and Hepatology, Department of Internal Medicine Toho University Medical Center, Omori Hospital 6-11-1, Omorinishi Ota-ku, Tokyo 143-8541 (Japan)

E-Mail manabu62@med.toho-u.ac.jp 


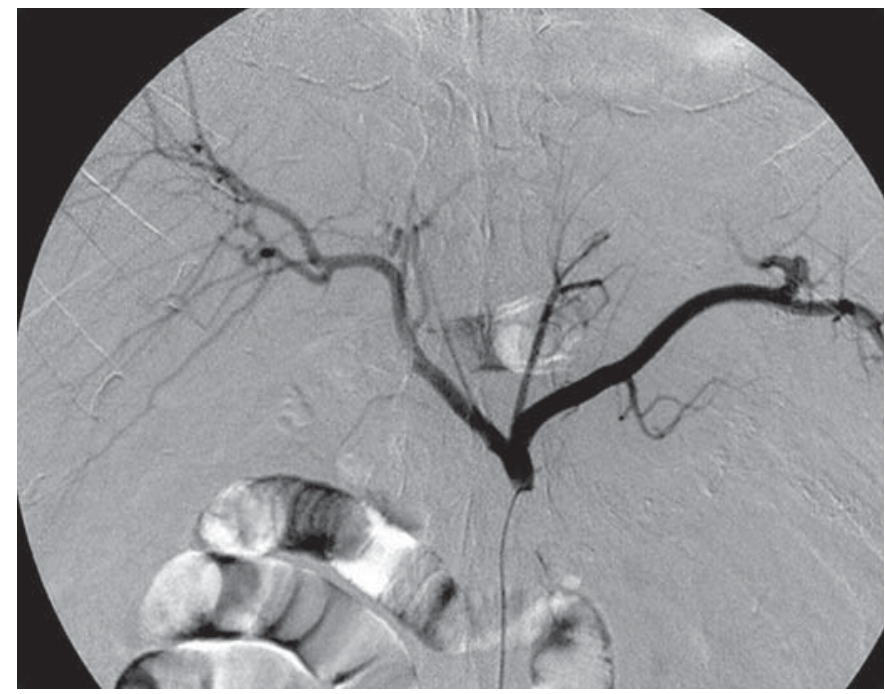

Fig. 1. Celiac artery angiogram revealed a normal variation of the vessel.

\section{Case Report}

The patient was a 32-year-old male with the primary complaint of upper abdominal pain. He was diagnosed with severe acute pancreatitis on the basis of clinical findings and laboratory data, and was admitted to the Intensive Care Unit of our hospital. He was managed by artificial ventilation and maintenance dialysis. Moreover, the case was diagnosed as severe acute pancreatitis and consistent with the report of Takeda et al. [4], abdominal angiography was performed (fig. 1), and treatment by continuous intra-arterial infusion of proteinase inhibitors and antibiotics was initiated. The patient was discharged on the 61st hospital day. Incomplete fusion of the pancreatic ducts was diagnosed by endoscopic retrograde cholangiopancreatography, and was considered to have caused the acute pancreatitis. Thereafter, the patient regularly visited our hospital and he was followed up by laboratory investigations and dynamic computed tomography (CT). However, the patient was admitted again after about 1 year due primarily to upper abdominal pain. Blood tests upon admission showed elevated amylase (AMY) (1,356 IU/l; normal: 24-137 IU/l), P-AMY (1,322 IU/l; normal: 11-49 IU/1), and white blood cell count $(16,400 / \mu \mathrm{l}$; normal: $4,000-9,000 / \mu \mathrm{l})$. Abdominal CT without contrast showed pancreatic enlargement with increased density of peripancreatic dirty fat tissue and fluid collection in the right anterior pararenal space. A diagnosis of reactivation of acute pancreatitis was made, and treatment was initiated. Abdominal dynamic CT on the 21st hospital day revealed a $16-\mathrm{mm}$ diameter spindle-shaped aneurysm in the right hepatic artery. At this time, no subjective symptom accompanying pseudoaneurysm was recognized. However, after the inflammatory reaction, AMY and P-AMY became normalized, and on the 37th hospital day, abdominal angiography was carried out via the left femoral artery, thus delineating a pseudoaneurysm measuring $18.5 \mathrm{~mm}, 8.5 \mathrm{~mm}$ at the root of the anterior segmental branch of the right hepatic

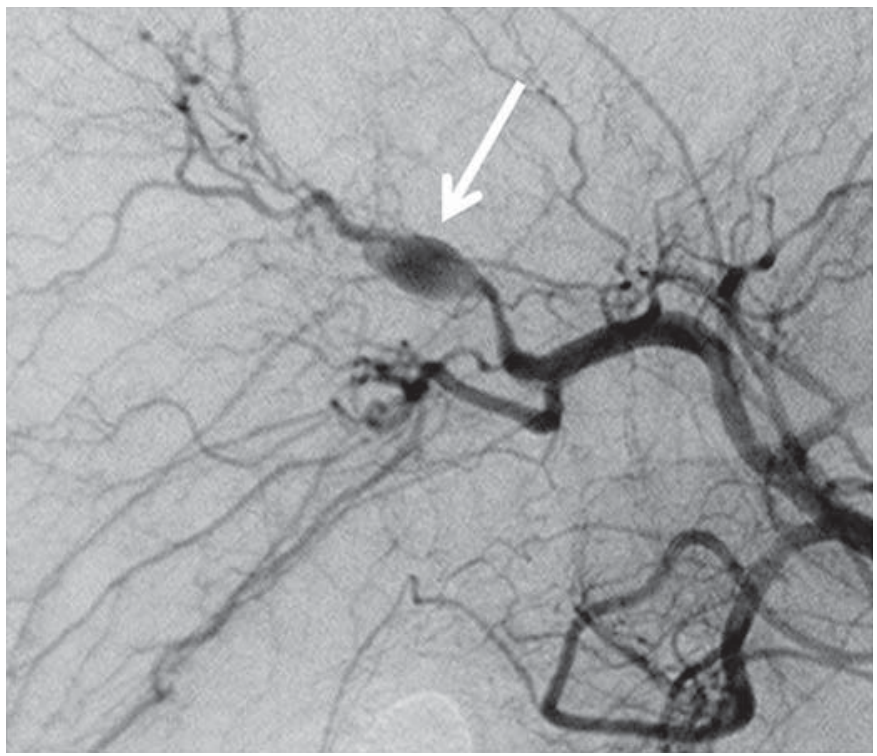

Fig. 2. Celiac artery angiogram revealed pseudoaneurysm of the right hepatic artery (arrow).

artery (fig. 2). A 5-French balloon catheter was placed in the right hepatic artery. A microcatheter was led into the pseudoaneurysm in the right hepatic artery, 3 coils (complex coils: $16 \mathrm{~mm} / 30 \mathrm{~cm}$, $14 \mathrm{~mm} / 30 \mathrm{~cm}$ and $5 \mathrm{~mm} / 15 \mathrm{~cm}$ ) were placed, after 1 coil (complex coil: $7 \mathrm{~mm} / 21 \mathrm{~cm}$ ) was placed in the right hepatic artery on the distal side of the pseudoaneurysm, and 1 coil (minicomplex coil; $4 \mathrm{~mm} / 10 \mathrm{~cm}$ ) was placed on the proximal side of the pseudoaneurysm using the isolation method. All coils used were TruFill ${ }^{\circledR}$ DCS coils (Cordis Corporation, Tokyo Japan). The absence of contrast agent influx into the pseudoaneurysm was confirmed. The postoperative course was uneventful, and the patient was discharged on the 44th hospital day.

\section{Discussion}

We experienced a rare case of right hepatic artery pseudoaneurysm complicating acute pancreatitis for which imaging findings were obtained before and after the development of pseudoaneurysm. However, Sethi et al. [5] had reported that $40 \%$ of pseudoaneurysms due to pancreatitis occur in the splenic artery, $30 \%$ in the gastroduodenal artery, $20 \%$ in the pancreatico-duodenal artery, $5 \%$ in the gastric artery, and $2 \%$ in the hepatic artery, indicating that they occur frequently in proximal arteries, where fluid is likely to be retained, among the arteries related to the pancreas, thereby implying that a pseudoaneurysm can occur in the common or proper hepatic arteries [5, 6]. While there have been sporadic reports of hepatic artery pseudoaneurysms complicating pancreati- 
tis [7], only 2 cases of right hepatic artery pseudoaneurysm distal to the proper hepatic artery have been reported $[8,9]$. However, these 2 cases had anomalous hepatic artery division, and our patient is the only case of right hepatic artery pseudoaneurysm with a normal arterial variation to be reported. In this patient, the inflammation was suggested to have diffused to a wide area, and the enzyme-rich fluid that spread around the pancreas was considered to have infiltrated along Glisson's sheath and caused the formation of a right hepatic artery pseudoaneurysm. Thus, a pseudoaneurysm may develop at any site into which fluid could infiltrate. Since pseudoaneurysm rupture is fatal, careful evaluation of the arteries around the pancreas as well as those in a wide area, including distal parts of the hepatic artery, is necessary in imaging examination on admission and at follow-up.

Usually, a pseudoaneurysm develops 3-5 weeks after the onset of acute pancreatitis, but pseudoaneurysm hemorrhage may occur from a few days to several years after the onset of pancreatitis [10]. This patient underwent abdominal angiography at the same time as the placement of the catheter for intra-arterial infusion during the 1st hospitalization. No pseudoaneurysm formation was noted in the right hepatic artery or at any other site at this time. Acute pancreatitis recurred after about 1 year, and dynamic CT and abdominal angiography performed upon re-admission revealed a pseudoaneurysm in the right hepatic artery.

\section{Conclusion}

This patient with a rare right hepatic artery pseudoaneurysm complicating acute pancreatitis was successfully treated with coil embolization.

\section{References}

1 Steer ML: Pathophysiology and pathogenesis of acute pancreatitis; in Bradley III EL (ed): Acute Pancreatitis: Diagnosis and Therapy. New York, Raven Press, 1994.

$>_{2}$ Bergert $\mathrm{H}$, Hinterseher I, Kersting S, Leonhardt J, Bloomenthal A, Saeger HD: Management and outcome of hemorrhage due to arterial pseudoaneurysms in pancreatitis. Surgery 2005;137:323-328.

-3 Balthazar EJ, Fisher LA: Hemorrhagic complications of pancreatitis: radiologic evaluation with emphasis on CT imaging. Pancreatology 2001;1:306-313.
4 Takeda K, Matsuno S, Ogawa M, Watanabe $S$, Atomi Y: Continuous regional arterial infusion (CRAI) therapy reduces the mortality rate of acute necrotizing pancreatitis: results of a cooperative survey in Japan. J Hepatobiliary Pancreat Surg 2001;8:216-220.

-5 Sethi H, Peddu P, Prachalias A, Kane P, Karani J, Rela M, Heaton N: Selective embolization for bleeding visceral artery pseudoaneurysms in patients with pancreatitis. Hepatobiliary Pancreat Dis Int 2010;9:634-638.

6 Siegelman SS, Copeland BE, Saba GP, Cameron JL, Sanders RC, Zerhouni EA: CT of fluid collections associated with pancreatitis. AJR Am J Roentgenol 1980;134:11211132.

7 Singh CS, Giri K, Gupta R, Aladdin M, Sawhney H: Successful management of hepatic artery pseudoaneurysm complicating chronic pancreatitis by stenting. World J Gastroenterol 2006; 12:5733-5734.
8 Rao RC, Kumar A, Berry M: Pseudoaneurysm of anomalous right hepatic artery as a cause for hemosuccus pancreatitis. Gastrointest Radiol 1987;12:313-314.

\9 Falkoff GE, Kenneth JW, Taylor SM: Hepatic artery pseudoaneurysm: diagnosis with realtime and pulsed Doppler US. Radiology 1986;158:55-56.

10 Dorffel Y, Wruck U, Ruckert RI, Romaniuk P, Dorffel W, Wermke W: Vascular complications in acute pancreatitis assessed by color duplex ultrasonography. Pancreas 2000; 21:126-133. 